\title{
ESTUDO DA AÇÃO EMULSIFICANTE DA POLPA DE ABACATE ASSOCIADA ÀS PROTEÍNAS DO SORO DE LEITE
}

\section{Study of the emulsifying action of the avocado pulp associated with the whey protein}

\author{
Marta de Oliveira Coelho ${ }^{1 *}$, Suélen de Oliveira Rezende ${ }^{l}$ \\ Mariana Gavioli dos Reis Pena ${ }^{l}$, Fabiano Freire Costa ${ }^{I}$
}

\begin{abstract}
RESUMO
O abacate é uma fruta rica em gorduras monoinsaturadas. O soro lácteo apresenta ação emulsificante e a sua combinação com outros componentes naturais pode ser potencializada formando novos produtos estáveis e atrativos ao consumidor. O presente estudo avaliou se a polpa de abacate poderá agir como agente emulsificante na fase oleosa de uma emulsão para fins alimentícios. Foi preparada uma emulsão básica com e sem a polpa de abacate. Estas emulsões foram pasteurizadas e microfluidizadas (Mixer e Turrax). Foram realizados testes de estabilidade (com e sem variações de temperaturas) e condição de armazenamento, teste de escoamento, liofilização, caracterização das amostras por tamanho de partícula e análise microscópica. Os resultados mostraram que a estabilidade da emulsão com abacate foi inferior à emulsão base. No estudo de escoamento as amostras das emulsões com abacate tiveram uma maior quantidade de massa perdida. Foi comprovada que houve um aumento da viscosidade pela ação emulsificante proveniente da polpa de abacate e ocorreu uma redução do tamanho das partículas dessa emulsão.
\end{abstract}

Palavras-chave: emulsão; temperatura; microscopia; tamanho de partícula.

\begin{abstract}
Avocado is a fruit rich in monounsaturated fats. Dairy whey has an emulsifying action and its combination with other natural components can be potentiated by

1 Universidade Federal de Juiz de Fora, Departamento de Ciências Farmacêuticas, Faculdade de Farmácia. Rua Lourenço Kelmer, s/n, São Pedro, 36036-900, Juiz de Fora, MG, Brasil E-mail: martacoelho395@ gmail.com

* Autor para correspondência.
\end{abstract}

Recebido / Received: $30 / 06 / 2018$

Aprovado / Approved: 23/10/2018 
forming new products that are stable and attractive to the consumer. The present study evaluated whether the avocado pulp can act as an emulsifying agent in the oil phase of an emulsion for food purposes. A basic emulsion was prepared with and without the avocado pulp. These emulsions were pasteurized and microfluidized (Mixer and Turrax). Stability tests (with and without temperature variations) and storage condition, flow test, lyophilization, characterization of samples by particle size and microscopic analysis were performed. The results showed that the stability of the emulsion with avocado was lower than the base emulsion. In the study of flow the samples of the emulsions with avocado had a greater amount of mass lost. It has been proven that there was an increase in viscosity by the emulsifying action from the avocado pulp and a reduction in the particle size of that emulsion occurred.

Keywords: emulsion; temperature; microscopy; particle size.

\section{INTRODUÇ̃̃̃O}

Uma emulsão se forma a partir de uma fase aquosa, no qual estão dispersas as proteínas da composição e uma fase oleosa que contém os lipídios, que homogeneizados formam gotículas estabilizadas pelo emulsificante para que não ocorra uma separação de fases. As emulsões de óleo em água são amplamente utilizadas para diversas funções como encapsulação, proteção e ou mesmo como veículo de componentes lipossolúveis permitindo o controle da absorção lipídica facilitando o aumento da acessibilidade dos compostos bioativos. A emulsão é formada por um sistema termodinamicamente instável que pode ser desestabilizado ao longo do tempo, e isso é possível devido aos fatores físico-químicos, como a separação gravitacional, a floculação, a coalescência e o amadurecimento de Ostwald (McCLEMENTS, 2004).

Devido à instabilidade das emulsões é comumente utilizado um emulsificante, sendo este o principal agente de estabilização que é também responsável também pela manutenção da homogeneização, determinação do tamanho das gotículas formadas por dois líquidos imiscíveis reduzindo a tensão interfacial do sistema e a formação de um biofilme de proteína em torno da gordura (GUPTA et al., 2016). Algumas característi- cas da camada interfacial que está ao redor das gotículas lipídicas em emulsões como polaridade, espessura da camada, composição química e pressão das moléculas carregadas são necessárias para conseguir um bom produto emulsificado (GOMES et al., 2018).

O soro lácteo é comumente utilizado devido sua constituição rica em proteínas como $\beta$-lactoglobulina ( $\beta$-LG) e $\alpha$-lactoalbumina $(\alpha-\mathrm{LA})$, além da grande quantidade de aminoácidos essenciais (PENA et al., 2017). Sendo assim, as proteínas presentes no soro lácteo possuem propriedades funcionais bastante relevantes para produtos alimentícios, como boa solubilidade, estabilidade, emulsibilidade, geleificação, possibilidade de formar biofilmes e cápsulas protetoras (COELHO et al., 2017; MODLER, 2000; WONG et al., 1996). Além disso, estas proteínas possuem alta digestibilidade, e um elevado valor nutritivo favorecendo o apelo para a base de um alimento natural e saudável, entretanto, são altamente sensíveis por causa da degradação e agregação do soro proteico. Desta forma, verifica-se grande importância do emulsificante na formulação em concentração ideais para não ocorrer a desestabilização do sistema coloidal, em razão das forças repulsivas estéricas ou eletrostáticas geradas entre as gotículas, uma vez que a estabilidade é o ponto principal das emulsões 
(BAI; McCLEMENTS, 2016; CHEVALLIER et al., 2018; JUNQUEIRA et al., 2018; SGARBIERI, 2005).

$\mathrm{Na}$ composição da fase oleosa pode ser utilizada uma gordura natural como a do abacate. Uma fruta com a polpa, cuja textura é muito suave, rica em gorduras monoinsaturadas (cerca de $32 \%$ ) e baixa quantidade de gordura insaturada, além de cinco fosfolípides naturais, fibras solúveis e insolúveis, que são propriedades funcionais e de grande benefício a saúde. Entretanto, possui também componentes como taninos, fenóis e pigmentos que podem causar algum tipo de alergenicidade, embora não tenham sido relatados com grande frequência na população problemas relacionados a essa potencial alergenicidade, sendo, portanto, de baixa relevância (ARAÚJO et al., 2018). Além disso, essa polpa pode ser utilizada pelas indústrias alimentícias como surfactantes e emulsificantes naturais devido às suas propriedades interfaciais, o que leva um alto valor agregado ao produto final (DREHER; DAVENPORT, 2013; ZÜGE et al., 2017). As diversas concentrações de cada fosfolipídio podem influenciar nas características das emulsões (DICKINSON, 1993). Além do mais, possuem teores bem significativos de fitoesteróis, esteróis e vitaminas A, D e E, e por conter um alto teor de ácidos graxos, principalmente o ácido oleico. A sua composição de ácidos graxos auxilia na diminuição do colesterol LDL (colesterol "ruim"), aumenta o colesterol HDL (colesterol "bom") no sangue reduzindo a incidência de doenças cardiovasculares sendo utilizado como um alimeto nutracêutico (LOGARAJ et al., 2008; ZÜGEL et al., 2017).

Os alimentos nutracêuticos são alimentos funcionais, o qual seu consumo fornece nutrientes benéficos à saúde (KHORASANI et al., 2018). Esses nutrientes e compostos não-nutrientes em alimentos possuem propriedades em prol da saúde, ou seja, auxiliam na prevenção de doenças ou em proprieda- des médicas (CAMIRE, 2003). E, são funcionais pois exercem efeitos farmacológicos, desta forma os compostos bioativos ou nutrientes adicionam a funcionalidade aos alimentos (YEUNG et al., 2018). Sabe-se que os resíduos e subprodutos agrícolas são atualmente de grande relevância para a produção de alimentos naturais. Isso favoreceu a produção de alimentos funcionais a partir de subprodutos para a promoção da saúde, dentro do setor lácteo como veículo de bioativos essenciais ao organismo e a boa saúde. Desta forma, o desenvolvimento de alimentos novos e produtos alimentícios funcionais torna-se bastante desafiador, visto que os consumidores estão cada vez mais exigentes nos aspectos sensorial e palatabilidade do alimento. No entanto, a aceitação de um ingrediente funcional específico ou de um alimento está relacionada à capacidade de entendimento do consumidor sobre a ação e os efeitos desses em sua saúde. Por isso é importante que sejam intensificados os conceitos de sustentabilidade e de saúde para que a demanda do consumidor em torno desses alimentos seja um dos principais objetivos de seu consumo (IRIONDO-DEHOND et al., 2018). Sendo assim, o objetivo desse trabalho foi avaliar a ação emulsificante das gorduras presente na polpa de abacate em uma emulsão com proteínas do soro lácteo.

\section{MATERIAL E MÉTODOS}

\section{Materiais}

Foram utilizados soro do leite em pó $\operatorname{Lac}^{\circledR}$ com 10,0\% de proteína (fornecido pela empresa Italac, Jaru, Rondônia, Brasil), goma xantana (adquirido na empresa Macalé, Juiz de Fora, Minas Gerais, Brasil), óleo vegetal de girassol Lisa ${ }^{\circledR}$, sacarose de confeiteiro União ${ }^{\circledR}$, emulsificante Esmutab ${ }^{\circledR}$ e polpa de abacate, adquiridos no comércio local da cidade de Juiz de Fora, Minas Gerais, Brasil. $\mathrm{O}$ emulsionante Pluronic e a água deioniza- 
da foram disponibilizados pelo Laboratório de Pesquisa em Alimentos (LPA) da Universidade Federal de Juiz de Fora (UFJF), Faculdade de Farmácia.

\section{Preparo das emulsões}

Foram preparadas dois tipos de emulsão: a emulsão base sem adição de polpa de abacate (A) e a emulsão com adição de polpa de abacate (B). As emulsões foram preparadas solubilizando a sacarose, o soro de leite e a goma xantana em água deionizada sob aquecimento $\left(70{ }^{\circ} \mathrm{C}\right)$. Em seguida a solução foi processada no aparelho Mixer (Fisaton) com rotação constante de $1.000 \mathrm{rpm}$ por 15 minutos. O óleo vegetal foi acrescentado à mistura aos poucos durante a agitação e, em seguida, adicionou-se a polpa de abacate previamente triturada. Posteriormente, a emulsão passou por um processo de pasteurização lenta a $65^{\circ} \mathrm{C}$ por 30 minutos. As emulsões foram levadas ao aparelho de Turrax (FSH -2A) a $17.000 \mathrm{rpm}$ por 5 minutos e 17.000 por mais 3 minutos para as emulsões (C e D) com a adição do emulsionante em pequenas quantidades. As quantidades estão apresentadas na Tabela 1 e os tratamentos na Tabela 2 (McCLEMENTS; RAO, 2011; PENA et al., 2017).

Tabela 1 - Quantidades dos componentes de cada emulsão

\begin{tabular}{lcc}
\hline Componentes & $\begin{array}{c}\text { Emulsão } \\
\text { Base } \\
(\%)\end{array}$ & $\begin{array}{c}\text { Emulsão } \\
\text { com } \\
\text { Abacate (\%) }\end{array}$ \\
\hline Soro de leite & 10,0 & 10,0 \\
Óleo Vegetal & 20,0 & 9,6 \\
Sacarose & 5,0 & 5,0 \\
Emulsionante & 0,1 & 0,1 \\
Surfactante & 0,0005 & 0,0005 \\
Goma xantana & 0,25 & 0,25 \\
Água deionizada & 64,6 & 50,2 \\
Polpa de Abacate & -- & 25,0 \\
\hline
\end{tabular}

Tabela 2 - Tratamentos aplicados a cada emulsão

\begin{tabular}{cl}
\hline Emulsão & \multicolumn{1}{c}{ Tratamentos } \\
\hline $\mathrm{A}$ & Emulsão Base em microfluidizador \\
\hline $\mathrm{B}$ & $\begin{array}{l}\text { Emulsão com abacate em } \\
\text { microfluidizador }\end{array}$ \\
\hline $\mathrm{C}$ & $\begin{array}{l}\text { Emulsão Base em nanofluidizador } \\
\text { Turrax }\end{array}$ \\
\hline $\mathrm{D}$ & $\begin{array}{l}\text { Emulsão com abacate em nano- } \\
\text { fluidizador Turrax }\end{array}$ \\
\hline
\end{tabular}

\section{Análise macroscópica}

Após o preparo das emulsões foi realizada análise visual com uma pequena quantidade das amostras verificando a viscosidade, a formação de agregados e a textura através do tato (JUNQUEIRA et al., 2018).

\section{Relação entre massa e tempo de descon- gelamento}

As amostras das emulsões foram congeladas em triplicata em freezer durante 6 horas. Foram retiradas do congelador e colocadas em um funil de $65 \mathrm{~mm}$. O tempo em que a primeira atingiu o béquer por gotejamento foi determinado. Assim, foram anotadas as massas descongeladas de 3 em 3 minutos em ambiente com temperatura controlada (PENA et al., 2017).

\section{Liofilização}

As amostras de cada uma das emulsões ( $\mathrm{A}, \mathrm{B}, \mathrm{C}$ e D), microfluidizada e nanofluidizada foram congeladas por 48 horas e, então, liofilizadas (Liofilizador LJJ0, Científica JJ) sob temperatura de $-44,4{ }^{\circ} \mathrm{C}$ e vácuo à $176 \mathrm{mmHg}$, durante 24 horas (ARAÚJO et al., 2018). 


\section{Estabilidade ciclo de congelamento/ descongelamento}

Para estudo de separação de fases após o descongelamento das emulsões foram utilizadas pequenas porções das amostras A, $\mathrm{B}, \mathrm{C}$ e $\mathrm{D}$ de $5,0 \mathrm{~mL}$ em tubos transparentes e tampados hermeticamente devidamente congelados $\left(-15^{\circ} \mathrm{C}\right)$ e descongelados num ciclo diário de 10 horas de descongelamento e 14 horas de congelamento no total de 11 dias. A cada ciclo de congelamento e descongelamento foi realizada a observação visual e registro fotográfico (PENA et al., 2017)

\section{Estabilidade}

Porções de $5 \mathrm{~mL}$ de cada uma das emulsões foram acondicionadas em frascos transparentes e hermeticamente tampados. Foram armazenadas sob condições de refrigeração $\left(5{ }^{\circ} \mathrm{C}\right)$, durante 30 dias. Diariamente foram realizadas análises visuais da emulsão e devidamente registradas por meio de fotografias (LAGO et al., 2018).

\section{Caracterização das emulsões}

\section{Tamanho da partícula}

O tamanho das partículas nas emulsões foi medido utilizando o equipamento LS Particle Size Analyzer (Beckman Coulter LS 13 320) (GOMES et al., 2018).

\section{Microscopia}

Foi utilizado microscópio digital USB para visualização das estruturas após a liofilização e microscópio Olympus DP72 para visualização da dispersão das gotículas (PENA et al., 2017).

\section{RESULTADOS E DISCUSSÃO}

\section{Análise visual das emulsões}

Ambas as emulsões A e B mostraram-se bem consistentes e com uma boa estabilidade, uma vez que permaneceram visualmente homogêneas. Não foram verificadas, na análise visual, alterações de escoamento entre as duas emulsões, porém foi observado um fluxo contínuo e aspecto bem cremoso. Verificou-se que a adição do emulsificante ocasionou o aumento da viscosidade das emulsões, quando foi adicionada a polpa de abacate rica em fosfolipídios, devido a característica de possuírem moléculas de água presas dentro dos flocos, que podem aumentar a fração volumétrica efetiva das partículas, aumentando também a cremosidade (McCLEMENTS, 2002). Desta forma, observou-se-se que a cremosidade e a viscosidade da emulsão estão inteiramente interligados ao escoamento e a capacidade de dispersão (LOGARAJ et al., 2008).

Foi possível observar visualmente tanto pelo tato quanto pelo aspecto que a emulsão base (A) apresentou-se menos viscosa que a emulsão com a polpa de abacate na escala macrométrica (B). Além disso, verificou-se que a emulsão (A), ao passar pelo aparelho de Turrax, apresentou alteração na coloração e na fluidez, ficando mais branca e mais fluida, pois a medida que o número de ciclos de microfluidização aumentou, a alta energia e a pressão exercida pelo microfluidificador geraram forças disruptivas muito fortes que foram capazes de romper a fase oleosa da fase aquosa, obtendo assim, gotículas bem finas de óleo com diâmetros mais homogêneos e mais uniformemente dispersos na fase aquosa. Desta forma, torna-se mais fácil a luz passar pelas partículas por dispersão, pois diminui a difração da luz, entretanto essa alteração foi bem menos perceptível na emulsão B (McCLEMENTS; RAO, 2011; RICAURTE, 2018). 


\section{Congelamento/Descongelamento e Estabilidade}

O ciclo de congelamento/descongelamento das amostras possibilita a verificação da capacidade das emulsões. Observa-se a capacidade de se manterem estáveis perante a variação da temperatura e como essa poderá ocasionar alterações visuais e na qualidade do produto. Há um grande interesse para relacionar a composição-estrutura de emulsões e sua estabilidade físico-química, e um dos fatores que podem alterar essa estabilidade é a variação de temperatura (GOMES et al., 2018). As amostras foram congeladas e no dia seguinte descongeladas, em um ambiente com temperatura controlada. De acordo com os resultados foi possível observar que houve alterações bastante significativas, após poucos dias de congelamento e descongelamento, sendo que a emulsão micro- fluidizada, na escala macrométrica (A), demorou mais dias para sofrer alteração.

As emulsões processadas no Turrax obtiveram uma estabilidade bem menor, possivelmente por causa da redução do tamanho de partícula e oxidação da polpa de abacate que ficou favorecida, uma vez que a fruta possui enzimas como peroxidase em alta quantidade e oxidase em baixa quantidade, $\mathrm{o}$ que favorece a oxidação, mas não o escurecimento de forma rápida quando exposto ao oxigênio (ZAFAR; SIDHU, 2011). Em contrapartida, a emulsão base permaneceu bastante estável por muitos dias, a emulsão A se manteve estável por 90 dias, enquanto a emulsão $\mathrm{C}$ desestabilizou-se em 30 dias, conforme mostra a Figura 1.

Como está demonstrado na imagem 2B na amostra da emulsão B (Figura 1), ocorreu um aumento no volume da amostra e formação de pequenas bolhas. Isso pode ser devido
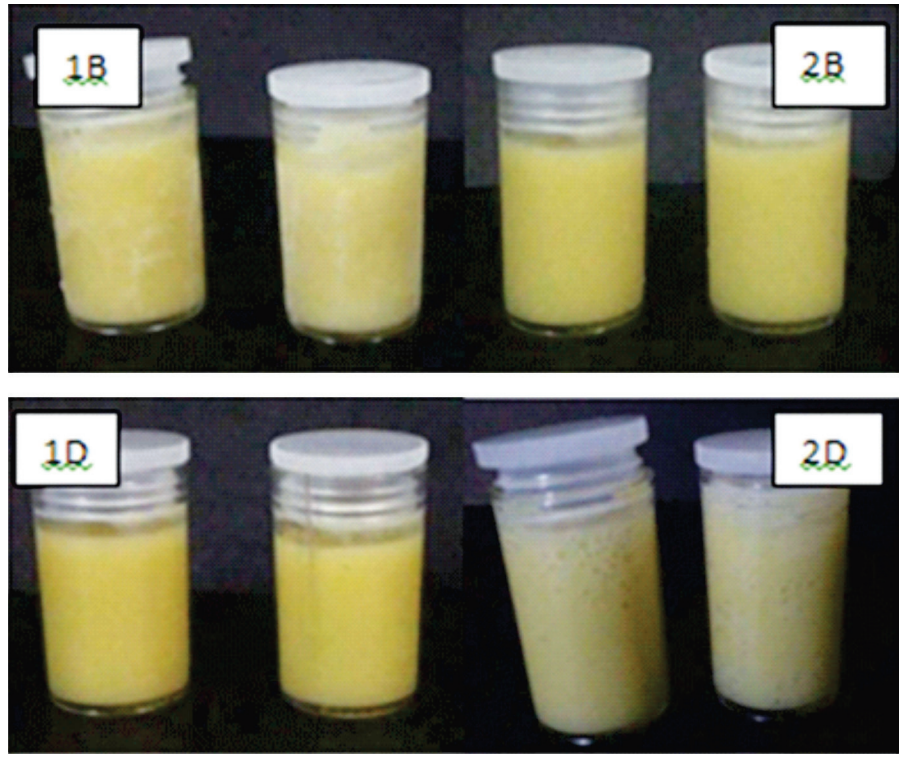

*(1B) Emulsão congelada no $1^{\circ}$ dia; (2B) Emulsão descongelada no $1^{\circ}$ dia; (1D) Emulsão congelada no $11^{\circ}$ dia; (2D) Emulsão descongelada no $11^{\circ}$ dia.

Figura 1 - Representação das amostras da emulsão com a polpa do abacate congelada e descongelada avaliando a estabilidade. Imagens da emulsão com a polpa de abacate microfluizada 
à fermentação aeróbica da amostra, uma vez que utilizamos polpa de abacate (fonte de nutrientes para crescimento de microrganismos, sem uso de conservantes), ou mesmo quebra da emulsão com separação de fase, ou seja, as pequenas bolhas que surgiram são bolhas de gordura que sofreram coalescência por ter reduzido ainda mais as gotículas na tentativa de torná-las nanogotículas, como visto na imagem $2 \mathrm{D}$. Outra possível causa para a rápida desestabilização da emulsão é o aumento do tamanho das partículas em virtude do congelamento e descongelamento, na qual pelo efeito anômalo da água, ela tende a aumentar quando congelada e isso pode ter interferido na estrutura da emulsão. Além disso, o tamanho das partículas da emulsão tem tendência a aumentar com o tempo de armazenamento (LOGARAJ et al., 2008). Entretanto, a emulsão A permaneceu estável por 90 dias, enquanto a emulsão C desestabilizou em 30 dias.

Após a análise da estabilidade das emulsões que foram mantidas sob refrigeração constante, observou-se que as amostras microfluidizadas permaneceram estáveis por cerca de 30 dias e as amostras nanofluidizadas ficaram por um período mais longo, cerca de 45 dias. Isso possivelmente ocorreu por causa da reticulação interfacial entres as proteínas do soro lácteo que foram adsorvidas melhorando a estabilidade física da emulsão nanofluidizada, inibindo a coalescência das gotículas floculadas (ZHU et al., 2018). Da mesma maneira a emulsão A foi analisada, e observou-se que ela permaneceu com estabilidade por mais de 90 dias, provavelmente pode ser devido a oxidação da polpa de abacate que influenciou na desestabilização da emulsão B. A estabilidade tem relação com o tamanho da partícula, a quantidade de gotículas presentes e seu padrão, ou seja, quanto menor o tamanho e quanto mais gotículas conter a amostra, mais estável é a emulsão, uma vez que a redução do tamanho de gotícu- la reduz a taxa de separação gravitacional, aumentando, assim, a estabilidade (DEPREE; SAVAGE, 2001). Além disso, uma grande quantidade de fosfolipídios proveniente do abacate na emulsão pode ter sua oxidação lipídica diminuída dependendo de alguns fatores, como propriedades moleculares, localização e condições ambientais, mantendo assim uma maior estabilidade da emulsão (McCLEMENTS; GUMUS, 2016).

A adição da polpa do abacate com o óleo e o emulsificante pode ter diminuído a tensão superficial, uma vez que foi percebida a homogeneidade após o preparo da formulação e durante o estudo de estabilidade o tempo durante o qual as amostras se mantiveram sem alterações. Possivelmente a desestabilização foi consequência do movimento das gotículas pela ação da força gravitacional, levando ao clareamento com formação de uma camada oleosa, aumento de volume e formação de bolhas oleosas nas amostras. Isso é possível uma vez que a nanofluidização transforma as partículas estáticas em nano partículas, comparando-se a um fluido de fluxo mais grosso. Esse processo interfere na alteração de coloração da emulsão (ZHU et al., 2016).

A quantidade de emulsificante necessária para estabilizar uma emulsão depende da carga superficial, que é determinada pela massa de surfactante por área de superfície unitária na saturação (OZTURK; McCLEMENTS, 2016). Além disso, a Força de Wan der Walls presente entre as gotículas da emulsão favorecem na sua estabilidade e quando elas são rompidas por algum fator físico ou químico ocorre a quebra da emulsão (LOGARAJ et al., 2008). Desta forma, o uso de emulsificante natural e de um residual, como o soro lácteo, no produto permite um apelo ecológico, pois além de evitar a contaminação ambiental com o soro lácteo, temos o apelo do produto saudável com o uso da polpa de abacate. Atualmente, as pessoas tendem 
a buscar produtos e ingredientes mais naturais ao invés de formas sintéticas, em prol de uma vida saudável, utilizando fontes de bioativos naturais. Sendo assim, o abacate demonstrou sua capacidade de estabilizar a emulsão e ser utilizado como um agente emulsificante natural. Entretanto, sua capacidade oxidativa é alta, necessitando de um agente antioxidante para uso em produto alimentício (IRIONDO-DEHOND et al., 2018).

\section{Taxa de descongelamento (massa/ tempo)}

Uma porção de cada amostra foi congelada durante algumas horas para verificar o tempo de escoamento da primeira gota após o descongelamento e o tempo total de escoamento de toda amostra. Após escoamento da primeira gota de cada amostra contou-se de três em três minutos e pesou-se a massa em gramas escoada, e depois foi calculada a massa perdida, e a partir desses dados a taxa de escoamento, conforme mostrado na Tabela 3. Sendo assim, podemos observar que a emulsão B demorou em torno de 20 minutos para escorrer uma quantidade média de $13 \mathrm{~g}$, além disso é possível ver que a quantidade de massa perdida foi de $21 \%$ da amostra apresentada. Em virtude disso podemos concluir que a emulsão apresentou viscosidade considerável, uma vez que demorou para escoar a primeira gota e para o escoamento total da amostra. Também observou-se que uma parte ficou retida na parede do frasco comprovando a alta viscosidade da amostra B.

Pode-se também observar que o tempo de escoamento da primeira gota da emulsão em que teve dois processamentos ( $\mathrm{C}$ e D) em média foi menor que da emulsão processada apenas uma vez (A e B), assim como o tempo total do escoamento das amostras o que inferimos que a viscosidade é menor do que a amostra em micro, pois quanto menor o tamanho da partícula, menos viscosa é a emulsão (LOGARAJ et al., 2008). Entretanto, a média de massa perdida foi de $20 \%$, ou seja, valores similares de ambas as emulsões, provavelmente devido a capacidade das gotículas em aderirem a parede do béquer devido sua composição mais lipofílica e não sendo relativa a viscosidade propriamente dita. Da mesma forma, verificou-se a emulsão A em sua análise de escoamento apresentou um tempo de escoamento em torno de 25 minutos, para aproximadamente 15 gramas da amostra da emulsão com redução do tamanho de partícula, sendo que houve uma perda de $15 \%$ da massa nas emulsões A e B e 9,5\% emulsões $\mathrm{C}$ e $\mathrm{D}$, o que implica na menor viscosidade da emulsão em que se reduziu o tamanho de partícula e por isso na menor perda de massa.

Tabela 3 - Dados de escoamento das emulsões

\begin{tabular}{|c|c|c|c|c|c|}
\hline \multirow{2}{*}{ Emulsões } & \multicolumn{5}{|c|}{ Escoamento* } \\
\hline & $\mathrm{T} 1$ (min) & $\mathrm{T} 2(\min )$ & M1 (g) & M2 (g) & M3 (g) \\
\hline A & 08:06 & $23: 13$ & $15,98 \pm 1,93$ & $13,56 \pm 0,59$ & $2,42 \pm 0,67$ \\
\hline B & $10: 11$ & $27: 14$ & $12,57 \pm 3,14$ & $14,08 \pm 4,12$ & $1,48 \pm 1,35$ \\
\hline $\mathrm{C}$ & $13: 02$ & $21: 16$ & $13,14 \pm 0,98$ & $10,37 \pm 0,43$ & $2,76 \pm 0,74$ \\
\hline $\mathrm{D}$ & $13: 14$ & $27: 14$ & $13,51 \pm 2,01$ & $10,81 \pm 1,62$ & $2,70 \pm 0,57$ \\
\hline
\end{tabular}

*T1 refere-se ao tempo gasto para escorrer a primeira gota da amostra e o T2 é o tempo total do escoamento da amostra. M1 refere a massa escorrida da primeira gota, M2 é a massa total que escorreu durante o experimento e M3 é o que ficou retira no béquer, ou seja, a massa perdida no experimento. 


\section{Liofilização}

O processo de liofilização é um processo comumente utilizado em indústrias para conservação do material altamente perecível, ou seja, é usado para preservar a qualidade e neste caso, como tratamos de uma emulsão com uso de propriedades naturais como o abacate, foi usada para evitar o escurecimento enzimático que constitui o principal problema de oxidação da fruta (ARAÚJO et al., 2018). Após a realização do processo de liofilização foram observadas que ambas as emulsões apresentaram características bastante oleosas, conforme mostrado na Figura 2. De acordo com as imagens, pode-se verificar que a estruturas das emulsões duplamente processadas (C e D) apresentaram diferenças, possivelmente devido a diferença do tamanho das gotículas das emulsões, além disso a emulsão microfluidizada teve sua apresentação bastante uniforme, com poros regulares e visualmente mais seca (Imagens A e B). As emulsões que foram processadas no nanofluidizador Turrax apresentaram formação de poro irregulares, presença de buracos em sua amostra e mais oleosa, isso possivelmente é devido a redução das partículas que favorecem com que elas se agregassem com mais facilidade (Imagens C e D). As amostras de liofilização tanto da emulsão base como da emulsão com abacate apresentaram semelhanças.
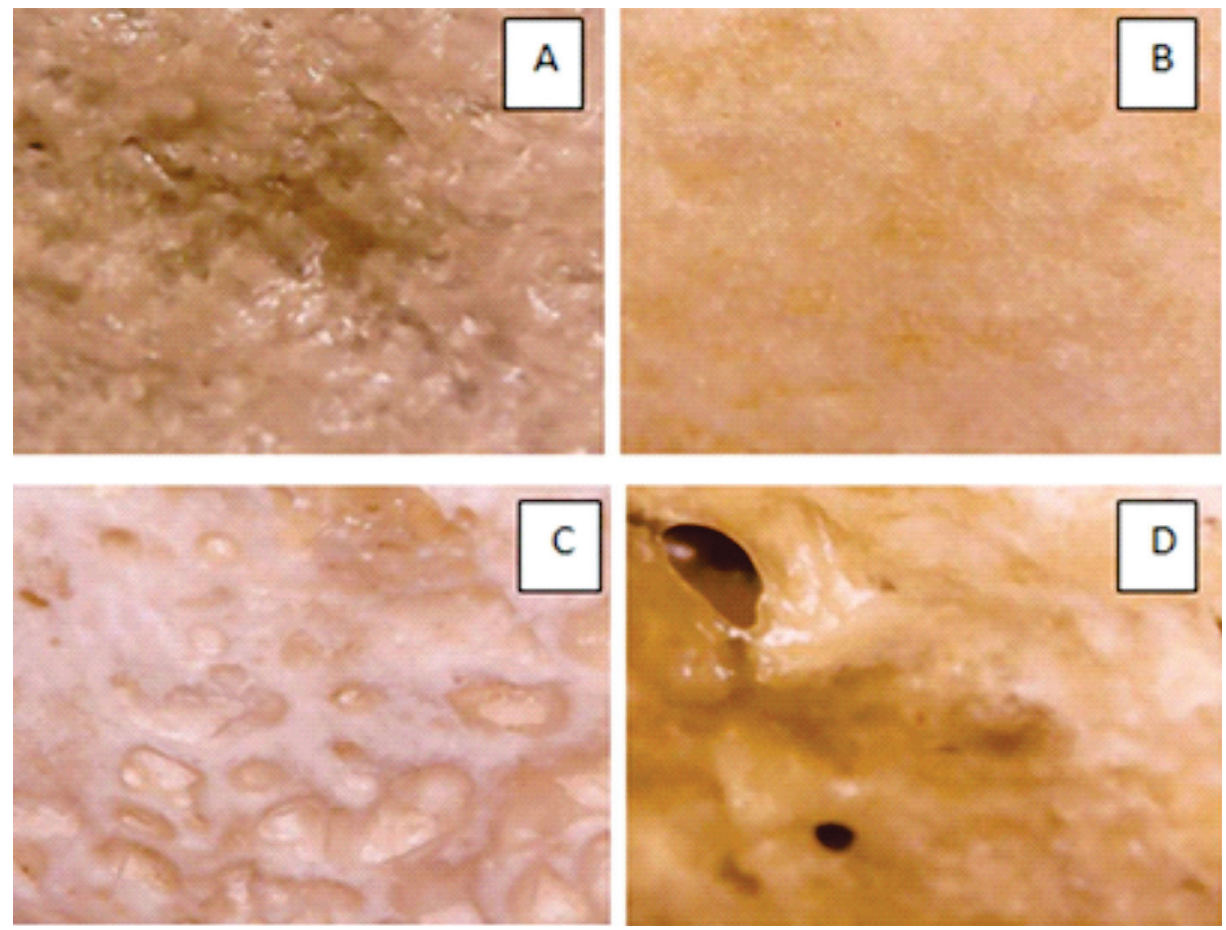

Imagens liofilização: (A) Emulsão básica microfluidizada liofilizada; (B) Emulsão com polpa do abacate microfluidizada liofilizada; (C) Emulsão básica nanofluidizada liofilizada; (D) Emulsão com a polpa de abacate nanofluidizada liofilizada.

Figura 2 - Representação da emulsão após o processamento de liofilização 


\section{Microscopia}

Foi realizada a análise de micrografia eletrônica das emulsões A, B, C e D, conforme mostra a Figura 3. As emulsões A e B foram microfluidizadas, sendo possível observar perfeitamente a formação de bolhas de gordura com o halo bem delimitado de proteína, com diferentes tamanhos e bem dispersos, enquanto as emulsões $\mathrm{C}$ e $\mathrm{D}$ passaram pelo nanofluidizador, assim podemos verificar que há uma uniformidade de bolhas de tamanho bem reduzido, o que nos levaram a crer que realmente houve redução do tamanho das gotículas, conforme as Imagens $\mathrm{C}$ e $\mathrm{D}$, comparada à $\mathrm{A}$.
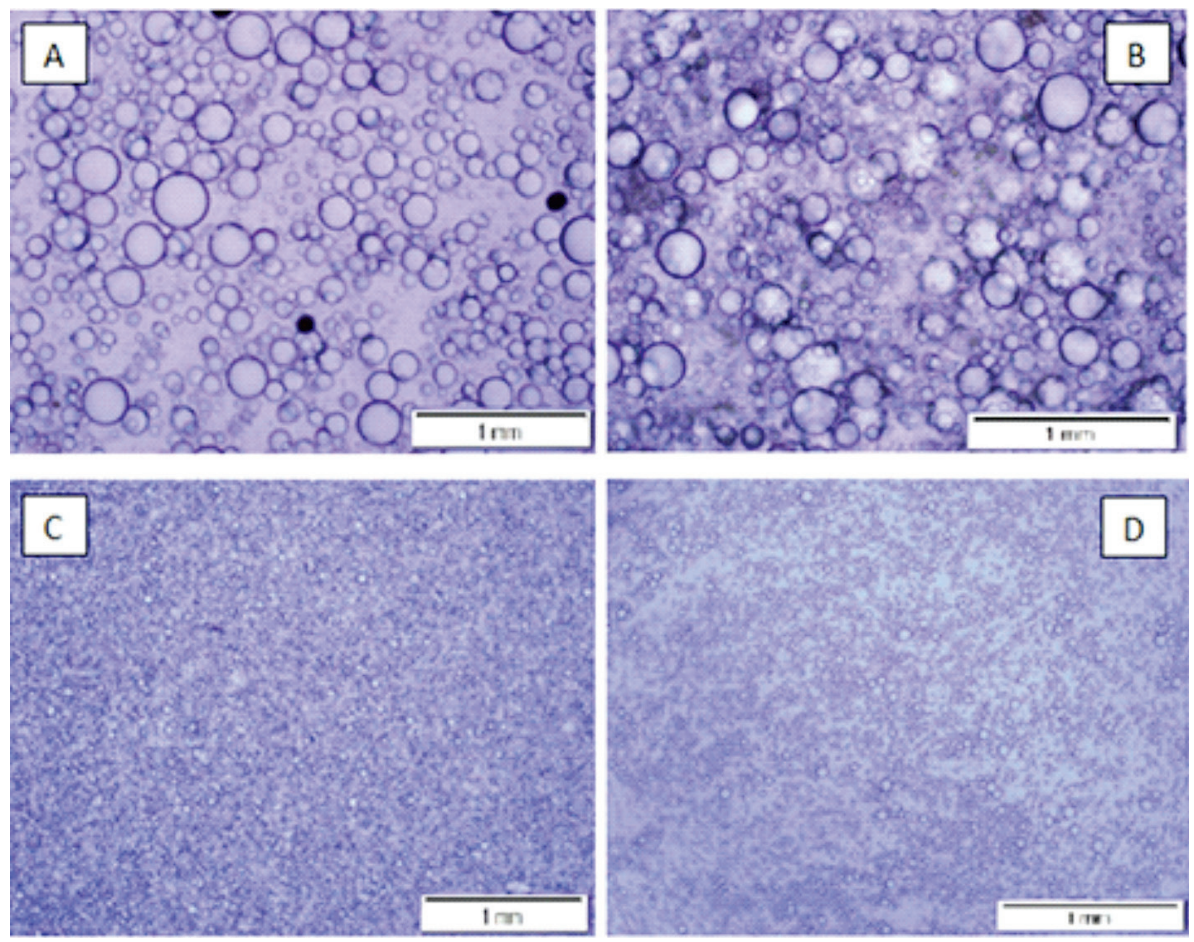

Imagem A refere-se a Microscopia eletrônica da Emulsão base no Microfluidizador; Imagem B refere-se a Microscopia eletrônica da Emulsão com abacate no Microfluidizador; Imagem C refere-se a Microscopia eletrônica da Emulsão base no Nanofluidizador Turrax; Imagem D refere-se a Microscopia eletrônica da Emulsão com abacate no Nanofluidizador Turrax.

Figura 3 - Representação microscópica eletrônica relacionando o tamanho das partículas 
foco maior em novos produtos e ao processo produtivo, de forma que o estudo baseado em nanociência vem empreendendo em variados campos industriais e na área de saúde (LAGO et al., 2018). A análise do tamanho de partícula das emulsões mostram que, partindo da emulsão microfluidizada para a emulsão com a polpa de abacate ao passar pelo nanofluidizador, houve uma redução do tamanho das gotículas, porém elas não atingiram uma escala nanométrica. Entretanto, esse mesmo resultado não foi possível observar na emulsão base, na qual apresentou valores um pouco maiores, conforme podemos observar na Tabela 3. Desta forma, é visto que a emulsão A possui gotículas com um tamanho médio de $72,67 \mu \mathrm{m}$, sendo que $10 \%$ e $90 \%$ das partículas possuem tamanho, respectivamente, $28,91 \mu \mathrm{m}$ e $134,2 \mu \mathrm{m}$, enquanto as gotículas da emulsão $\mathrm{C}$ que foi processada no nanofluidizador obtiveram um tamanho médio de $94,91 \mu \mathrm{m}$ e $10 \%$ das partículas com tamanho $3,65 \mu \mathrm{m}$ e $90 \%$ com $170,2 \mu \mathrm{m}$. Assim, sugere-se que a redução não foi em grandes proporções, porém o desvio padrão também foi elevado o que implica que apenas algumas partículas reduziram de tamanho (D10). Isso também pode ser verificado através da alteração de cor, pois as emulsões macométricas são mais turvas e opacas pois as gotículas possuem dimensões semelhantes ao comprimento de luz e por isso dispersam a luz (McCLEMENTS; RAO, 2011).

Em relação aos dados da emulsão com abacate B verificou-se gotículas com um tamanho médio de $96,34 \mu \mathrm{m}$, sendo que $10 \%$ e $90 \%$ das partículas possuem tamanho respectivamente, $28,91 \mu \mathrm{m}$ e $1134,2 \mu \mathrm{m}$, enquanto as gotículas da emulsão D apresentaram um tamanho médio de 25,52 $\mu \mathrm{m}$ e $10 \%$ das partículas com tamanho $2,39 \mu \mathrm{m}$ e $90 \%$ com $69,14 \mu \mathrm{m}$, sugerindo que houve redução do tamanho de partícula, o que foi comprovado com a redução do desvio pa- drão da análise. Contudo, a emulsão ainda não conseguiu adotar a escala micrométrica, uma vez que os tamanhos das gotículas e suas classificações são que as macroemulsões possuem tamanhos de gotículas variando de 0,1 a $100 \mu \mathrm{m}$. As microemulsões comumente tem a presença de um emulsificante para formar o complexo estabilizado, apresentando uma estabilidade menor devido a tensão superficial inferior e possuem o tamanho de gotícula também menor, em torno de 0,1 a $100 \mathrm{~nm}$. As nanoemulsões apresentam tamanhos de gotículas com um diâmetro médio de 20 a $200 \mathrm{~nm}$. Portanto, as emulsões estão presentes na escala manométrica, mais estáveis termodinamicamente e, por isso, possuem estabilidade maior que as microemulsões (JUNQUEIRA et al., 2018).

Tabela 4 - Dados dos valores de tamanho de partículas

\begin{tabular}{ccccc}
\hline Tratamento & \multicolumn{4}{c}{ Tamanho de partícula $(\mu \mathrm{m})^{*}$} \\
\hline & D10 & D90 & Ma & DP \\
A & 28,91 & 134,20 & 76,67 & 41,12 \\
B & 21,02 & 156,30 & 96,34 & 130,70 \\
C & 3,65 & 170,2 & 94,91 & 61,76 \\
D & 2,39 & 69,14 & 25,52 & 29,55 \\
\hline
\end{tabular}

*D10 representa $10 \%$ das partículas analisadas; D90 representa $90 \%$ das partículas analisadas, Ma é a média aritmética dos valores de tamanho de partícula analisadas; e DP é o desvio padrão dos valores de Ma.

\section{CONCLUSÕES}

Constatou-se a atividade emulsificante do abacate frente a formulação de emulsão base com ingredientes simples como: soro do leite, óleo vegetal, sacarose, emulsificante, surfactante, goma xantana, água deionixada e polpa do abacate. Esta constatação tem grande importância considerando que 
o abacate pode reduzir a concentração ou até mesmo substituir alguns compostos sintéticos e gorduras, que não são benéficos à saúde. Verificou-se também uma redução do tamanho da partícula na emulsão contendo a polpa de abacate, contemplando sua ação emulsificante, associada ao soro lácteo. Conclui-se que a polpa de abacate apresentou ação emulsificante, juntamente com o soro lácteo, podendo ser utilizados na produção de emulsões como bases de produtos alimentícios. Destaca-se também nesse estudo que não houve incompatibilidade entre a polpa do abacate e o soro de leite, agregando sustentabilidade pelo reaproveitamento do soro do leite e compostos funcionais e nutricionais encontrados no abacate, que além de auxiliarem na estabilidade da formulação atuam como componentes de nutrientes ao organismo no produto final.

\section{AGRADECIMENTOS}

Agradecemos a Universidade Federal de Juiz de Fora pelo fornecimento da Bolsa BIC de Iniciação Científica pelo projeto Produção de Micro e Nanopartículas a partir de Biopolímeros Naturais, ao laboratório de Núcleo de Espectroscopia e Estrutura Molecular (NEEM) do departamento de Química da Universidade Federal de Juiz de Fora, em especial ao professor Dr. Rodrigo Stephani, ao laboratório de Desenvolvimento do Sistema Nanoestruturado LDNano do professor Dr. Frederico Pitella Silva e também ao professor Dr. Saulo Marçal Souza pela realização das análises microscópicas.

\section{REFERÊNCIAS}

ARAÚJO, R. G.; et al. Avocado by-products: Nutritional and functional properties. Trends in Food Science \& Technology, v. 80, p. 51-60, 2018.

BAI, L.; McCLEMENTS, D. J. Develop- ment of microfluidization methods for efficient production of concentrated nanoemulsions: Comparison of single - and dualchannel microfluidizers. Journal of Colloid and Interface Science, v. 466, p. 206-212, 2016.

CAMIRE, M. E. Nutraceuticals for health promotion and disease prevention. Cast, Council for Agricultural Science and Technology, v. 24, p. 1-16, 2003.

CHEVALLIER, M.; et al Increasing the heat stability of whey protein-rich emulsions by combining the functional role of WPM and caseins. Food Hydrocolloids, v. 76, p. 164-172, 2018.

COELHO, M. O.; et al. Suero lácteo enbrasil: panorama y necesidad de reaprovechamiento. Tecnología Láctea Latinoamericana, v. 98, p. 16-20, 2017.

DEPREE, J. A.; SAVAGE, G. P. Physical and flavor stability of mayonnaise. Trends in Food Science and Technology, v. 12, p. 157-163, 2001 .

DICKINSON, E. Towards more natural emulsifiers. Trends in Food Science and Technology, p. 330-334, 1993.

DREHER, M. L.; DAVENPORT, A. J. Hass avocado composition and potential health effects. Food Science and Nutrition, v. 53, p. $738-750,2013$.

GOMES, A.; et al. Impact of oil type and WPI/Tween 80 ratio at the oilwater interface: Adsorption, interfacial rheology and emulsion features. Colloids and $S$ urfaces B : Biointerfaces, v. 164 , p. $272-280,2018$.

GUPTA, A.; et al. Nanoemulsions: formation, 
properties and applications. Soft Matter, v. 12, n. 11, p. 2826-2841, 2016.

IRIONDO-DEHOND, M.; MIGUEL, E.; DEL CASTILLO, M. D. Byproducts as a source of novel ingredients in dairy foods. In: FERRANTI, P.; BERRY, E. M.; ANDERSON, J. R. (Eds.). Encyclopedia of Food Security and Sustainability - Module in Food Science. [s.1.] Elsevier Inc., 2018. p. 316-322.

JUNQUEIRA, L. A.; et al. Rheological behavior and stability of emulsions obtained from Pereskia aculeata Miller via different drying methods. International Journal of Food Properties, v. 21, n. 1, p. 36-50, 2018.

KHORASANI, S.; DANAEI, M.; MOZAFARI, M. R. Nanoliposome technology for the food and nutraceutical industries. Trends in Food Science \& Technology, v. 79, p. 106-115, 2018.

LAGO, A. M. T. Nanoemulsão de óleo-emágua produzida com mucilagem de orapro-nóbis por meio de homogeneizador ultrassônico. 2018. Tese (Doutorado em Farmácia) - Departamento de Alimentos, Universidade Federal de Lavras, Lavras, MG, 2018.

LOGARAJ, T. V.; et al. Rheological behaviour of emulsions of avocado and watermelon oils during storage. Food Chemistry, v. 106, p. 937-943, 2008.

McCLEMENTS, D. J. Colloidal basis of emulsion color. Current Opinion in Colloid \& Interface Science, v. 7, n. 5-6, p. 451-455, 2002.

McCLEMENTS, D. J. Protein-stabilized emulsions. Current Opinion in Colloid \& Interface Science, v. 9, n. 5, p. 305-313, 2004.

McClements, D. J.; GUMUS, C. E.
Natural emulsifiers-biosurfactants, phospholipids, biopolymers, and colloidal particles: Molecular and physicochemical basis of functional performance. Advances in Colloid \& Interface Science, v. 234, n. 1, p. 3-26, 2016.

McCLEMENTS, D. J.; RAO, J. Food-grade nanoemulsions: formulation, fabrication, properties, performance, biological fate, and potential toxicity. Critical Reviews in Food Science and Nutrition, v. 51, n. 4, p. 285330, 2011.

MODLER, H. W. Milk processing. In: NAKAI, S.; MODLER, W. (Eds.). Food proteins: processing applications. [s.1.] WileyVCH Inc., 2000. p. 1-21.

OZTURK, B.; McClements, D. J. Progress in natural emulsifiers for utilization in food emulsions. Current Opinion in Food Science, v. 7, n. 1, p. 1-6, 2016.

PENA, M. G. R.; et al. Producción de micro y nanopartículas a base de biopolímeros naturales: estudio de la estabilidad de emulsiones a base de suero lácteo. Tecnología Láctea Latinoamericana, v. 98, p. 48-54, 2017.

RICAURTE, L. Physical, thermal and thermodynamical study of high oleic palm oil nanoemulsions. Food Chemistry, v. 256, p. $62-70,2018$.

SGARBIERI, V. C. Revisão: Propriedades estruturais e físico-químicas das proteínas do leite. Brazilian Journal of Food Technology, v. 8, n. 1, p. 43-56, 2005.

WONG, D. W. S.; CARMIRAND, W. M.; PAVLAT, A. E. Structures and functionalities of milk proteins. Food Science and Nutrition, v. 36, n. 8, p. 807-844, 1996. 
YEUNG, A. W. K.; MOCAN, A.; ATANASOV, A. G. Let food be thy medicine and medicine be thy food: A bibliometric analysis of the most cited papers focusing on nutraceuticals and functional foods. Food Chemistry, v. 269 , p. $455-465,2018$.

ZAFAR, T.; SIDHU, J. S. Avocado: production, quality, and major processed products. In: SINHA, N. K. (Ed.). Handbook of Vegetables and Vegetable Processing. $1^{\mathrm{a}}$ ed. [s.1.] Blackwell Publishing Ltd., 2011. p. 525-543.
ZHU, Y.; et al. ion- and temperature-dependent emulsion gels: Fabricated by addition of whey protein to gliadin-nanoparticle coated lipid droplets. Food Hydrocolloids, v. 77, p. 870878, 2018.

ZHU, X.; et al. Review on the nanoparticle fluidization science and technology. Chinese Journal of Chemical Engineering, v. 24, n. 1, p. 9-22, 2016.

ZÜGE, L. C. B., et al. Use of avocado phospholipids as emulsifier. LWT - Food Science and Technology, v. 79, p. 42-51, 2017. 